\title{
Identification of parametric policy options for rehabilitating a pay-as-you-go based pension system: an optimization analysis for Turkey
}

\section{Serdar Sayan \& Arzdar Kiraci}

To cite this article: Serdar Sayan \& Arzdar Kiraci (2001) Identification of parametric policy options for rehabilitating a pay-as-you-go based pension system: an optimization analysis for Turkey, Applied Economics Letters, 8:2, 89-93, DOI: 10.1080/13504850150204129

To link to this article: https://doi.org/10.1080/13504850150204129

Published online: 06 Oct 2010.

Submit your article to this journal $\sqsubset$

Џ Article views: 41

4 Citing articles: 3 View citing articles ๘ 


\title{
Identification of parametric policy options for rehabilitating a pay-as-you-go based pension system: an optimization analysis for Turkey
}

\author{
SERDAR SAYAN* and ARZDAR KIRACI \\ Department of Economics, Bilkent University, 06533 Ankara, Turkey
}

Received 14 May 1999

Publicly managed pension systems operating on the basis of pay-as-you-go (PAYG) schemes face financial difficulties worldwide. The expenditure-revenue balances of such a system are determined jointly by the selected configuration of system parameters, and interrelated developments in the labour market and demographic structure. In a country where pension coverage is compulsory, these developments occur completely beyond the control of pension system administrators implying that any imbalances that may arise over time can be corrected only by adjusting the existing configuration of contribution and replacement rates, and minimum retirement ages. It can be shown, however, that there are infinitely many configurations of these system parameters that could be used to maintain a selected intertemporal balance between the amounts of contributions collected from workers and pensions paid to the retirees. This paper describes an algorithm developed to identify all possible configurations compatible with this goal and illustrates its use with reference to the pension reform debate in Turkey, a country whose PAYG-based pension system already faces a severe financial crisis despite a relatively young workforce/population. The results indicate that for contribution and replacement rates to remain around their current values, the minimum retirement age must be increased substantially.

\section{INTRODUCTION}

Publicly managed pension systems based on pay-as-you-g o (PAYG) schemes face financial difficulties worldwide. These systems use contributions collected from currently active workers to pay pension benefits to eligible retirees who have previously contributed to the system. The contributions for each worker are determined by multiplying the wage/salary income with the applicable payroll tax rates, whereas the retirement incomes are calculated by using replacement rates that tie pension payments to wages/salaries earned prior to retirement. Since wages/ salaries are determined in the labour market, the preretirement incomes out of which contributions are collected and by which levels of pension payments are determined are exogenous to the pension system. While the relevant rates can be adjusted to control the amounts of contribution receipts and pension payments per individual, total revenues and expenditures of the entire system depend on the numbers of active workers and retirees covered. But these numbers themselves are largely determined by demographics implying that in a country where coverage

*Corresponding author: e-mail: sayan@ bilkent.edu.tr 
is compulsory, a publicly managed system can keep these under check only by setting minimum contribution periods. Pension authorities and policy makers of such a country, therefore, have essentially three parameters to adjust, whenever exogenous changes occurring over time seriously disturb the revenue-expenditure balances of the PAYGbased system: contribution and replacement rates, and minimum contribution periods (retirement ages).

When a growing pension deficit signals the need for parametric pension reform as it is sometimes called (Chand and Jaeger, 1996), existing values of pension parameters must be changed within politically acceptable limits so as to eliminate (or curb the growth in) pension deficits. Theoretically, however, there are infinitely many configurations of these three parameters that are compatible with the maintenance over time of a selected balance between contribution receipts and pension expenditures, and informing policy makers of the choices available to them requires identification of possible configurations.

The present paper considers this identification issue in an intertemporal setting as in generational accounting studies (Auerbach et al., 1991). For this purpose, a simple optimization model is developed and applied to the case of parametric reform options before Turkey, a country whose publicly managed, PAYG-based pension system already faces a severe financial crisis despite a relatively young population/workforce. Unlike other countries where similar pension systems face financial difficulties largely because of population ageing over the course of their demographic transition, a major reason behind the crisis of Turkish system is the retirement ages that are exceptionally low ${ }^{1}$ by international standards (Sayan and Kenc, 1999). ${ }^{2}$ The evident need to increase minimum contribution periods/retirement ages distinguishes pension reform efforts in Turkey from the experience of other countries where policy makers had little room to adjust retirement ages along with other two parameters. So, the numerical optimization algorithm used here has been developed to solve for optimal values of all three policy parameters simultaneously.

The optimization approach and its implementation are described in the next two sections. The results are presented in Section IV where the implications of results are briefly discussed.

\section{THE NUMERICAL OPTIMIZATION FRAMEWORK}

The approach outlined in this section links up well with the growing pension reform literature as briefly surveyed by
Chand and Jaeger (1996). Particularly relevant examples of this literature can be found in Halter and Hemming (1987), Van den Noord and Herd (1994), and Boll et al. (1994) for other countries, and in ILO (1996) and Sayan and Ozgur (1999) for Turkey.

Alternative policy parameter configurations that will stop the growth of pension deficits over a specified period of time could be identified by solving the following minimization problem, subject to the values that exogenous variables are projected to take over time and non-negativity constraints:

$$
\begin{aligned}
\min _{C R, R R, A} D \equiv & \sum_{t=t_{0}}^{\tau} \frac{\chi}{(1+\delta)^{t^{\prime}}}\left(R R . \sum_{a=A}^{\ell} r w_{a, t-(a-A)-1} \cdot r_{a, t}\right. \\
& \left.-C R .>\sum_{a=a_{0}}^{A-1} r w_{a, t} w_{a, t}\right)
\end{aligned}
$$

where

$C R=$ average rate for employee and employer contributions combined,

$R R=$ average replacement rate tying pension benefits to wages earned by workers,

$A=$ minimum retirement age,

$\delta=$ discount rate,

$\chi=$ the fraction of wages on the basis of which contributions and pension payments are calculated (wage ceiling),

$r w_{a, t}=$ average real wage earned by workers at the age of $a$ at time $t$,

$w_{a, t}=$ number of workers at the age of $a$ at time $t$,

$r_{a, t}=$ number of retirees at the age of $a$ at time $t$,

$a=$ age index running from the beginning of working-life, $a_{0}$, to, life expectancy in years,

$t=$ time index running from initial period, $t_{0}$, to $\tau$, the end of model horizon, and

$t^{\prime}=t-t_{0}$

Given this notation, total pension payments at $t$ are calculated by multiplying the number of retirees in each age group $a$ with the applicable pension for that group, and summing over $a$. The applicable pensions are calculated through a simple indexation scheme requiring each retiree to be paid a certain proportion, $\chi, R R$, of the last real wage earned prior to retirement. Since a retiree aged $a \geqslant A$ at time $t$ must have been collecting pensions for the past $a-A$ years, the last pay check (s)he picked as a worker must be given in real terms by $r w_{a, t-(a-A) 1}$, implying that (s)he is entitled to collect $R R \%$ of this amount in pension payments. Each active worker aged $a<A$ at time $t$, on the other hand, is paid $r w_{a, t}$, and contributions are collected at

\footnotetext{
${ }^{1}$ Presently, it is possible in Turkey to retire as early as 38 years of age (James, 1995).

${ }^{2}$ For a comparison of the nature of demographic transition in Turkey to that in the European Union, see Kenc and Sayan (2000).
} 
Table 1. Growth of social security deficit in Turkey

\begin{tabular}{lll}
\hline Year & $\begin{array}{l}\text { Share of soc. sec. deficit } \\
\text { in total budget deficit }(\%)\end{array}$ & $\begin{array}{l}\text { Share of total transfers to } \\
\text { soc. sec. institutions in GNP (\%) }\end{array}$ \\
\hline 1993 & 17 & 1.20 \\
1994 & 20 & 1.13 \\
1995 & 36 & 1.44 \\
1996 & 26 & 2.16 \\
1997 & 34 & 2.55 \\
1998 & 35 & 2.85 \\
\hline
\end{tabular}

Source: Ayas (1998, pp. 48-49)

the rate of $C R$ out of $\chi \%$ of this income. $D$ in (1) therefore shows the difference between the sums of future (expected) pension payments and total contribution receipts in real present value terms. So, the problem can more precisely be formulated as finding the endogenously determined values of all $3 \times 1$ policy vectors [CR $R R A$ ] so as to minimize $D$, for given values of $\delta$ and $\chi$, and exogenous projection data on working and retiree populations and real wages. $^{3}$

\section{IMPLEMENTATION}

In implementing the algorithm developed for this purpose, the goal for Turkish pension system was set to have $D=0$ over the 1995-2060 period. Obviously, the alternative configurations could have been found also by requiring $D>0$, allowing the government to provide subsidies to pension institutions as a social policy. Even now, however, the existing system in Turkey absorbs most of the direct subsidies and transfers by the government as indicated in Table $1 .{ }^{4}$ Moreover, the total deficit of social security system is projected to increase to $16.8 \%$ of GNP by the year 2050 if the current pension parameters are to be retained. Even considering pension losses alone, the projections indicate that by 2010 , the GNP share of pension deficits is likely to exceed 5\% (Ayas, 1998).

Getting $D$ as close to 0 as possible is equivalent to the maintenance of the real deficit of the entire pension system in Turkey at its 1995 level. As the Turkish economy would continue to grow, this must be expected to lower the real
GDP share of pension deficit to a negligible level by the year 2060.

Within this set-up, projection data were fed into the computational algorithm developed for this purpose and the optimal ( $C R R R A)$ triplets were found. ${ }^{5}$ The projection data needed came from different sources and whenever necessary, new series were generated under appropriate assumptions. For population projections, the same data were used as the ILO (1996) study. Working population series was generated using these population projections under the assumption that workforce participation rates by gender and age in 1994 would remain the same as reported by SIS (1995). As for the retiree population, the ratio of the number of retirees to total population in 1995 was found using the numbers of voluntary retirees at each age group as reported in ILO (1996). Then, the projections concerning annual stocks of pensioners were generated under the assumption that this ratio would stay constant by the end of model horizon. The real wage projections were obtained by extending the series in Bulutay (1992) into 2060 using assumed rates of productivity growth and expected inflation. ${ }^{6}$ Finally, $\chi$ was taken to be $40 \%$ as in Gillion and Cichon (1996) and $d$ was set equal to 0.05 as in ILO (1996).

The algorithm run in Gauss requires that the following inequality be satisfied for each configuration of parameters: ${ }^{7}$

$$
\begin{array}{|}
\mid \begin{array}{l}
\sum_{t=1995}^{2060} \frac{C R}{(1+\delta)^{t^{\prime}}}\left(\sum_{a=15}^{A-1} r w_{a, t} \cdot w_{a t}\right) \\
-\sum_{t=1995}^{2060} \frac{R R}{(1+\delta)^{t^{\prime}}}\left(\sum_{a=A}^{75^{+}} r w_{t-(a-A)-1, t} \cdot r_{a, t}\right) \mid
\end{array} \\
\quad \sum_{t=1995}^{2060} \frac{C R}{(1+\delta)^{t^{\prime}}}\left(\sum_{a=15}^{A-1} r w_{a, t} \cdot w_{a, t}\right) \\
+\sum_{t=1995}^{2060} \frac{R R}{(1+\delta)^{t^{\prime}}}\left(\sum_{a=A}^{75^{+}} r w_{t-(a-A)-1, t} \cdot r_{a, t}\right)<0.0001
\end{array}
$$

In searching for the optimal values, the following procedure was used. For each alternative value of $A$ considered, the $r_{a, t}$ series in the initial projection data was regenerated by transferring the retirees younger than $A$ to the working population. Then, the total present value of

\footnotetext{
${ }^{3}$ As such, the exercise focuses on pension balances alone and overlooks survivors' benefits, health care payments, or old-age benefits to the needy and other similar aspects of social security.

${ }^{4}$ The term 'social security system' here refers to the collection of three publicly managed institutions: Bag-Kur (BK), Emekli Sandigi (ES) and Sosyal Sigortalar Kurumu (SSK), each offering pension, health and disability benefits to different groups within the working population. For more information, see, for example, Sayan and Ozgur (1999).

${ }^{5}$ In order to limit the scope of analysis to essential details only, the $C R$ and $R R$ values in the optimal configurations are taken here as average rates that would commonly apply to all three institutions.

${ }^{6}$ It was assumed that the rate of labour productivity growth would be maintained at its $1950-1989$ average of $2.73 \%$ calculated from Bulutay (1992). Expected inflation rates were assumed to be equal to previous year's rate until 1998 and to be the following thereafter: $50 \%$ for $1998-2000$; $20 \%$ for $2000-$ $2005 ; 10 \%$ for $2005-2010,5 \%$ for $2010-2020$, and $3 \%$ for $2020-2060$.

${ }^{7}$ It can be shown that this amounts to minimizing $D$ in (1) to the desired degree of precision. Requiring that the ratio in (2) be strictly smaller than 0.00001 rather than 0.0001 , for example, would increase the precision.
} 


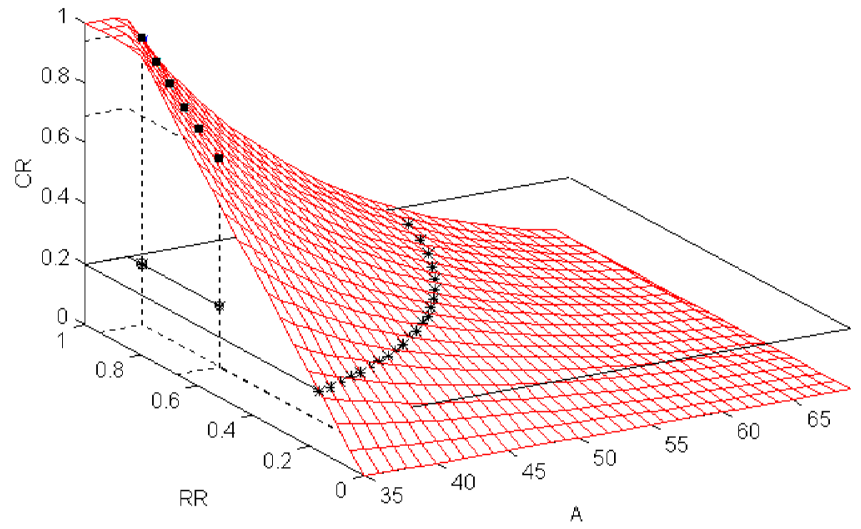

Fig. 1. $C R, R R$ and $A$ configurations for minimizing the intertemporal pensions deficit in Turkey, 1995-2060

real pension payments was calculated by changing the $R R$ with increments of 0.05 within the interval $[0,1]$ for this new value of $A$. After storing the results from this stage, a search routine was employed to find $C R$ s that will be compatible with the ratio in (2) being smaller than 0.0001 for each previously stored value of $R R$ and the associated value of $A$. Finally, optimal configurations are plotted in three dimensions as shown in the next section.

\section{RESULTS AND CONCLUSIONS}

Figure 1 shows all $[C R R R A]$ configurations that are compatible with $D=0$ over the 1995-2060 period. The current situation is marked in the figure with the existing average $C R$ of $20 \%$ and a minimum allowable retirement age of 38 . Two stars marked show applicable $R R$ s for people covered by the largest two of the pension institutions, SSK and ES (TUSIAD, 1997). The bold black line in Fig. 1 shows the required (as opposed to actual) $C R \mathrm{~s}$ for these $R R \mathrm{~s}$ to be maintained by allowing people to retire as early as 38 years of age, and without allowing for a growth in pension deficits. The required contribution rates that correspond to $R R$ s of 0.67 (ES) and 0.95 (SSK) are 0.69 and 0.94 , respectively. Given the wage ceiling of $40 \%$, a $C R$ of $69 \%$ implies that $27.6 \%$ of the real wages earned have to be contributed to the system by white-collar workers covered by ES. For the higher $R R$ applicable to the pensioners of SSK, on the other hand, the required $C R$ of $95 \%$ implies a contribution level corresponding to $38 \%$ of the real wages earned by SSK workers.

The cross-section in Fig. 2 shows the locus of possible $(A, R R)$ combinations associated with $C R=20 \%$. The replacement rates of 0.67 and 0.95 marked in the figure indicate that current $R R \mathrm{~s}$ of ES and SSK would require minimum retirement ages varying between 53 and 56 , if the average $C R$ of $20 \%$ are to be retained.

Similar cross-section plots could be generated for other politically acceptable values of $C R \mathrm{~s}$ if the $R R \mathrm{~s}$ are to be

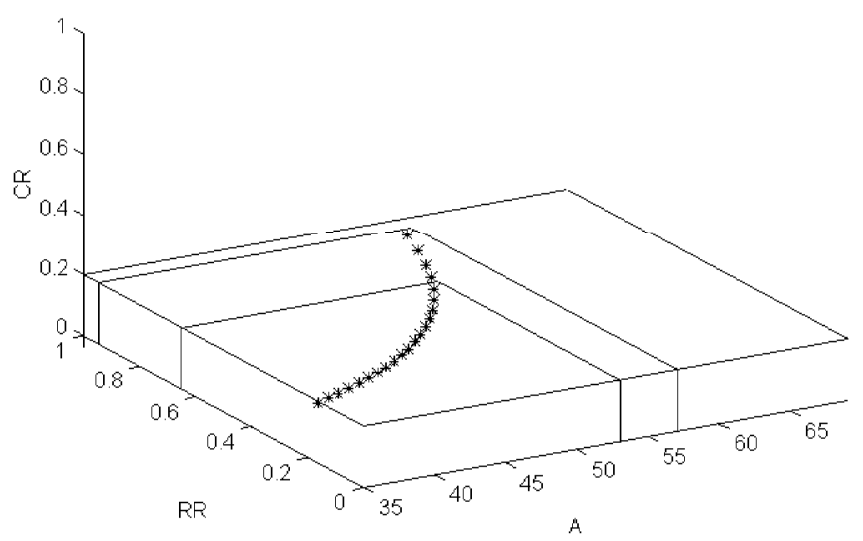

Fig. 2. Locus of $(A, R R)$ combinations for $C R=20 \%$

maintained at current values. Since each different configuration implies a different intergenerational distribution of pension system resources, the policy makers may opt to reduce $R R \mathrm{~s}$ as well. In general, once a consensus on the need to curb the growth of pension deficits is reached, the particular parameter vector picked would depend on the relative political powers of parties involved, e.g. retirees' associations, trade unions etc. It is obvious from the results, however, that for $C R \mathrm{~s}$ and $R R$ s to remain around their current values, the minimum retirement age must be increased significantly.

\section{ACKNOWLEDGEMENTS}

The authors express their thanks to Ms Secil Ozgur for her assistance in the compilation of data required for this study.

\section{REFERENCES}

Auerbach, A. J., Gokhale, J. and Kotlikoff L. J. (1991) Generational accounts: a meaningful alternative to deficit accounting, NBER Working Paper No. 3589, Cambridge, MA.

Ayas, E. (1998) Turkiye'de sosyal guvenlik sisteminin sorunlari ve cozum onerileri, Isletme ve Finans, 150, 41-50.

Boll, S., Raffelhuschen, B. and Walliser, J. (1994) Social security and intergenerational redistribution: a generational accounting perspective, Public Choice, 81, 79-100.

Bulutay, T. (1992) A General Framework for Wages in Turkey, SIS, Ankara.

Chand, S. K. and Jaeger, A. (1996) Aging populations and public pension schemes, IMF Occasional Paper 147, IMF, Washington, DC.

Gillion, C. and Cichon, M. (1996) Pension reform in Turkey, Hazine Dergisi (Special Issue on Social Security and Health Insurance Reform), 40-56.

Hagemann, R. P. and Giuseppe, G. N. (1989) Population aging: economic effects and some policy implications for financing public pensions, OECD Economic Studies, 12, 51-96. 
Halter, W. A. and Hemming, R. (1987) The impact of demographic change on social security financing, IMF Staff Papers, 34, 471-502.

ILO (1996) Social Security and Health Insurance Reform Project: Final Report, ILO, Geneva.

James, E. (1995) Averting the old-age crisis, Finance and Development, 32(2), 4-7.

Kenc, T. and Sayan, S. (2000) Transmission of demographic shocks from large to small countries: an overlapping generations CGE analysis, Journal of Policy Modeling (forthcoming).

Sayan, S. and Kenc, T. (1999) Long-term consequences of rehabilitating a financially troubled pension system: an overlapping generations, general equilibrium analysis for Turkey,
ERF Working Paper Series (forthcoming), Economic Research Forum, Cairo.

Sayan, S. and Ozgur, S. (1999) Getting SSK out of crisis: An analysis of parametric policy options for the largest pension fund administration in Turkey, Yapi Kredi Economic Review (forthcoming).

SIS (1995) Statistical Yearbook of Turkey 1994, Turkish State Institute of Statistics (SIS), Ankara.

TUSIAD (1997) Turk sosyal guvenlik sisteminde yeniden yapilanma: Sorular, reform ihtiyaci, arayislar, cozum onerileri, TUSIAD, Istanbul.

Van den Noord, P. and Herd, R. (1994) Estimating pension liabilities: A methodological framework, OECD Economic Studies, 23, 131-166. 